\title{
Measuring the Ponzo illusion with the method of production*
}

\author{
ALEXANDER W. PRESSEY \\ University of Manitoba, Winnipeg, R3T 2N2, Canada
}

\begin{abstract}
The Ponzo illusion was varied as a function of angle of oblique arms and was measured by the method of production. The results showed that the method of production produced very similar results to those obtained by the method of limits. The data also indicated that relatively stable individual scores could be obtained if about six judgments were required and if the targets elicited a large illusion. It was concluded that the method of production should be given serious consideration when choosing a psychophysical method.
\end{abstract}

In the method of production, the $S$ is asked to produce a stimulus (usually by drawing) that is related, in some specified way, to the standard stimulus. For example, in the Poggendorff illusion, the $S$ is asked to draw a dot on one of the parallel lines so that the transverse line appears to point to it (Pressey \& Sweeney, 1969; Velinsky, 1925). In the Mueller-Lyer illusion, the $S$ is asked to draw a line that appears equal to the standard stimulus (e.g., Bayer \& Pressey, 1972). In this latter case, the phrase "method of reproduction" has been employed.

Despite the simplicity of the technique, systematic investigations on the reliability and validity of the method of production have not been carried out. Some evidence is available on the Poggendorff illusion, in which reliability coefficients were found to range from .64 to .80 (Pressey \& Dewar, 1970; Pressey \& Sweeney, 1969). Evidence on the validity of the method is more indirect and stems mainly from the fact that variables which affect the illusion show the same trends when measured by the method of production as when measured by the more popular method of adjustment (Coren \& Girgus, 1972; Hill, 1971; Pressey \& Sweeney, 1972).

The major aim of the present study was to assess the validity of the method of production in measuring the Ponzo illusion. The Ponzo illusion, shown in Fig. 1, was chosen because evidence was already available on the manner in which the illusion changes as the angle of obliques varies (Pressey, Butchard, \& Scrivner, 1971). The method of limits had been employed in this previous study, and thus the data could be used as the validating criteria.

\section{METHOD}

\section{Subjects}

The Ss were 124 men and women enrolled in introductory psychology courses at the University of Manitoba. Only Ss who had good vision with or without glasses were asked to participate.

*This study was supported by the National Research Council of Canada. Reprints may be obtained from the Department of Psychology, University of Manitoba, Winnipeg, Manitoba, R3T 2N2, Canada.

\section{Materials}

Twenty targets were drawn with black ink on separate sheets of white paper, each of which was $27.8 \mathrm{~cm}$ high and $21.5 \mathrm{~cm}$ wide. There were 18 Ponzo and 2 control targets. In every target, the standard magnitude was a $50-\mathrm{mm}$ horizontal line. The oblique lines which formed the angle were $100 \mathrm{~mm}$ long and were positioned in such a fashion that $25 \mathrm{~mm}$ of that line was above and $75 \mathrm{~mm}$ was below the standard. There was no gap between the ends of the standard and the oblique lines. There were nine angles of the oblique lines; these were obtained by extending the obliques and measuring the angle at the apex. The angles were $10,20,30,40,50,60,90,120$, and $150 \mathrm{deg}$.

The perpendicular distance from the standard line to the position of the comparison line was $100 \mathrm{~mm}$. Since the method of production was employed, no comparison line was actually presented. Rather, a small black dot, which served as a starting point, was drawn in two positions for each angle. In the first position, it was $100 \mathrm{~mm}$ below and $8 \mathrm{~mm}$ to the left of the left edge of the standard; in the second position, it was $100 \mathrm{~mm}$

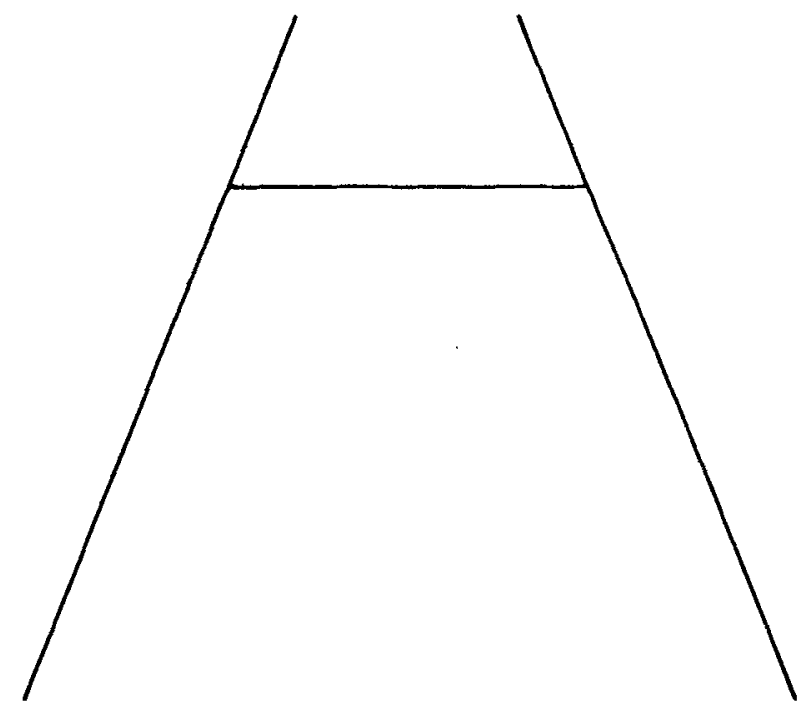

Fig. 1. The Ponzo illusion. 


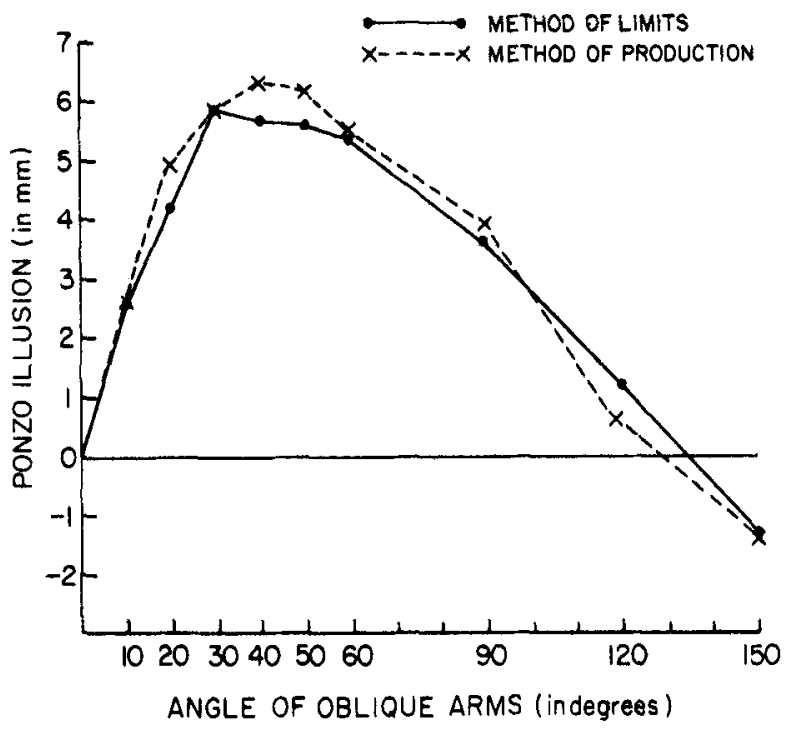

Fig. 2. The Ponzo illusion as a function of angle when measured by the method of production and thymethod of limits.

below and $8 \mathrm{~mm}$ to the right of the left edge of the standard. The control targets consisted of the standard line and the starting dot. The width of each contour was about $0.5 \mathrm{~mm}$ and the diameter of each dot was about $1 \mathrm{~mm}$.

The targets were reproduced by offset duplicating procedures. During testing, they were placed on a white wooden holder, $39.5 \mathrm{~cm}$ high and $37 \mathrm{~cm}$ wide, tilted backwards 20 deg. A chinrest was located directly in front of the holder so that the distance between $S$ 's eyes and the target was $41 \mathrm{~cm}$.

\section{Procedure}

$S$ placed his chin in the rest and was shown a sample target. His task was to draw a line on the target which appeared to be equal to the horizontal line. (This line was pointed out to him.) He was told to start from the dot and draw a horizontal line towards the right edge of the page. The $S$ was asked not to worry too much about making the line exactly straight or exactly horizontal, because $\mathrm{E}$ was interested primarily in the apparent size of the standard line.

The targets were presented manually and were centered on the target holder. Each $\mathrm{S}$ responded to one random order of the 10 targets, but two successive judgments of each target were made-one with the starting dot on the right and the other with the dot on the left. The order of starting positions was the same for all targets within a series but was counterbalanced between Ss.

The rate of presentation of targets was S-paced in the sense that, while $\mathrm{E}$ took approximately $3 \mathrm{sec}$ to remove one targe: $\mathrm{and}$ replace it with another, Ss varied in the time they took to make a response. After completion of the task, the $S$ was told the purpose of the study.

\section{RESULTS}

Measurements of the produced line were made with a straight-edge millimeter scale. These measurements were accurate to within $0.5 \mathrm{~mm}$. For each $\mathrm{S}$, the mean of the two judgments per angle was obtained, and the mean of the control targets was subtracted from this score to provide a measure of illusion. The mean illusion, as a function of angle, is shown in Fig. 2. Also shown in Fig. 2 are the data that were obtained previously with the method of limits. It should be emphasized that the dimensions of the targets and the viewing distance were almost identical in the two experiments, i.e., the entire figures were $1 \%$ larger in the previous study. The similarity of the two functions shown in Fig. 2 is striking not only in terms of the form of the function, but also in terms of the absolute size of illusion obtained. It appears that the method of production is as valid a technique as the method of limits for measuring the Ponzo illusion.

Crude estimates of reliability were also made. For example, product-moment correlation coefficients were calculated between the two productions at each angle. The coefficients ranged from .25 to .60 , with an average of .46. Application of the Spearman-Brown formula indicated that reliability coefficients of about .80 could be obtained by increasing the number of trials from two to eight. It is interesting to note, however, that the highest coefficients were found at the 30-, 40-, 50-, and 60-deg angles, indicating that the targets that produced larger illusions also produced a more stable ordering of responses. Thus, if a stable ordering of individuals is desired, the number of trials necessary will be directly related to size of the distortion that the target produces.

In the above estimates of reliability, the two starting positions provided quite different absolute sizes of illusion. As a consequence, it could be argued that the task was not identical on the two trials and that this produced an underestimation of the true reliability of the method. Another estimate of reliability was attempted. Since the means and variances of the illusions at the 30-, 40-, 50-, and 60-deg angles were very similar, product-moment correlation coefficients were calcualted using scores from adjacent angles as pairs. Separate coefficients calculated for the left and right starting positions ranged from .43 to .62 with a mean of .55 . These estimates indicate that a substantially stable score can be obtained with about six judgments, provided that the target elicits a large illusion.

\section{DISCUSSION}

Howard, Wagner, and Mills (1973) have argued that the choice of a psychophysical method is based upon three indices, viz, reliability, validity, and efficiency. The outstanding virtue of the method of production is its efficiency, because a large amount of data can be amassed with a minimum amount of testing. In the present study, total testing time was less than 15 min for each $S$ (including instructions and feedback). If boredom is a factor, this method might be desirable.

Group testing is also feasible with this method. If the need is to test organismic or personality variables, large samples can be handled readily with this method. Group testing has been employed (Pressey \& Sweeney, 1972), and the obtained functions have been replicated by others who have employed individual testing procedures. ${ }^{1}$ Finally, in regard to efficiency, the method does not require complex or bulky equipment. The limited demands for special space, transportation, or power is an asset.

The functional relationships that are produced by the method are very similar to those produced by other methods. Not only 
does Fig. 1 show the close relationship, but other data on the reversed Mueller-Lyer illusion (Pressey \& Bross, 1973) are consistent with previous work.

The method is not without weaknesses. Apparently, each individual score is not as stable as a score obtained by, say, the method of adjustment. If stable individual scores are required, then a relatively large number of trials may be necessary. On the other hand, a large number of trials could introduce unwanted learning effects and might precipitate boredom and carelessness.

In addition, certain variables cannot be studied extensively with this method, e.g., feasible viewing distance is generally restricted to the length of the S's arm. It is possible to study longer viewing distances with the addition of mechanical aids, but the difficulties involved are so great that other psychophysical methods undoubtedly would be more efficient.

In summary, the method of production provides valid data, is reliable, and is exceedingly efficient when used to measure geometric illusions. The method warrants serious consideration as a useful psychophysical technique.

\section{REFERENCES}

Bayer, C. A., \& Pressey, A. W. Geometric illusions as a function of pigmentation of the fundus occuli and target size. Psychonomic Science, 1972, 26, 77-79.

Coren, S., \& Girgus, J. S. A comparison of five methods of illusion measurement. Behavior Research Methods \& Instrumentation, 1972, 4, 240-244.

Hill, A. L. Poggendorff illusion: Effects of intelligence, viewing distance, and space between vertical lines. Psychonomic Science, 1971, 25, 71-72.

Howard, R. B., Wagner, M.. \& Mills, R. C. The superiority of the pair-comparisons method for scaling visual illusions. Perception \& Psychophysics, 1973, 13, 507-512.

Pressey, A. W., \& Bross, M. Assimilation theory and the reversed Müller-Lyer illusion. Perception, 1973, 2, 211-217.

Pressey, A. W., Butchard, N., \& Scrivner, L. Assimilation theory and the Ponzo illusion: Quantitative predictions. Canadian Journal of Psychology, 1971, 25, 486-497.

Pressey, A. W., \& Dewar, M. J. A reversed Poggendorff illusion. Psychonomic Science, 1970, 20, 227-228.

Pressey, A. W., \& Sweeney, O. A variation of the Poggendorff illusion. Perceptual \& Motor Skills, 1969, 28, 883-886.

Pressey, A. W., \& Sweeney, O. Some puzzling results on the Poggendorff illusion. Perception \& Psychophysics, 1972, 12 , 433-437.

Velinsky, S. Explication physiologique de l'illusion de Poggendorff. Année Psychologique, 1925, 26, 107-116.

\section{NOTE}

1. Personal communication from D. J. Weintraub at the University of Michigan and A. E. Wilson at Mount Allison University.

(Received for publication October 4, 1973; revision received March 21,1974 .) 